\title{
Study regarding the influence of airbag deployment time on the occupant injury level during a frontal vehicle collision
}

\author{
Alexandru Ionut Radu ${ }^{1, *}$, Corneliu Cofaru ${ }^{1}$, Bogdan Tolea ${ }^{2}$ and Dragoș Dima ${ }^{1}$ \\ ${ }^{1}$ Department of Automotive and Transport, Faculty of Mechanical Engineering, 500091 University “TRANSILVANIA” of Brasov, \\ Romania \\ ${ }^{2}$ Department of Mechanical Engineering and Automotive, 410610 University of Oradea, Romania
}

\begin{abstract}
The aim of this paper was to analyse the influence of airbag deployment delay upon the head of the occupant in the case of frontal collision using simulations in PC Crash and MADYMO dummy as the occupant. The study will also take into account the pretension delay of the seat-belt which is activated along with the airbag. Frontal airbags on both the passenger and the driver were analysed including the occupant kinematics during the collision. Also, to validate the simulation, a comparison was done with a real crash test. We predict that by increasing the delay of deployment, the head acceleration will increase due to the fact the head travels close to the instrument panel/steering wheel, and the force of the airbag will generate a significant acceleration upon the head. To better assess the potential injury of the occupant, the head injury criteria (HIC) will be calculated and correlated with the Abbreviated injury scale (AIS) code.
\end{abstract}

\section{Introduction}

The increasing number of vehicles during the last decades in the urban area, as well as the intensification of congestions in intersections has led to considerable roadaccident recordings [1]. Road traffic accident research has been conducted over the years in order to study of the dynamic and kinematic behaviour of the occupant in the impact phase as well as the injury assessment [2]. Since the introductions of airbags, lots of lives have been saved in motor vehicles crashes [3]. The airbag provides a good protection for all kinds of crashes (side and frontal) that could seriously injure or kill the occupants of the vehicle [4]. Huere has shown in a study that airbags can reduce head injuries by up to $82 \%$ for the $56-65 \mathrm{~km} / \mathrm{h}$ range. Using the airbag, it was demonstrated that in $85 \%$ of cases, head injuries were classified as minor injuries [5].

Airbags have been demonstrated to reduce car accident mortality by $19 \%$, and reduce morbidity from facial fractures and chest injuries. In purely frontal crashes, airbags reduce the fatality risk by $34 \%$ [6].

Airbags inflates when an electrical current provided by the airbag control unit is distributed to the detonator. The ignition starts a chemical reaction that produces nitrogen gas which rapidly inflates the nylon fabric bag. After the airbag has been fully inflated, the nitrogen gas is released through small vent holes at the side when the occupant's head hits and compresses the airbag. The small holes are constructed specifically in a size and spaced out to reduce the volume of the airbag at a different rate, depending on the type of vehicle. This gas is released alongside with dust particles that are from the material used to lubricate the airbag (typically talcum powder and corn-starch) [7]. There are multiple types of airbags (front, sides, knee and curtains) [8].

The head injury can be assessed by a parameter called HIC (Head Injury Criteria), defined by a mathematical formula. The HIC criterion is a way of assessing the risk of a cranial trauma injury as a result of an accident. The HIC criterion is the maximum standard value of the integral of the head acceleration. Depending on the interval for which it is calculated, the HIC criterion is: - Unlimited - HIC;

- 36 ms maximum - HIC36;

- 15 ms maximum - HIC15.

In order to predict the injury level of the occupant, the HIC formula takes into account the head acceleration on the occupant's head. The HIC formula is presented below [9], [10]

$$
H I C 36=\max _{t 1, t 2}\left[\left(t_{2}-t_{1}\right)\left(\frac{1}{t_{2}-t_{2}} \int_{t 1}^{t 2} a(t) d t\right)^{2.5}\right.
$$

Where: $\mathrm{t} 2$ - final time value (s), $\mathrm{t} 1$ - initial time value (s), $\mathrm{a}(\mathrm{t})$ - head acceleration resultant $(\mathrm{g})$

The acceleration value, according to the impulse duration, shows a maximum limit of $40 \mathrm{~g}$ for the head. In the case of pedestrians the situation is more dangerous, at the impact with the ground, much higher head accelerations (120 - $200 \mathrm{~g})$ can cause severe injuries. The head injury assessment is done using the HIC (Head Injury Criteria) criteria in a time interval of 36 milliseconds for the occupant, respectively $15 \mathrm{~ms}$ for the pedestrian [11], [12].

\footnotetext{
* Corresponding author: alexandru.radu@unitbv.ro
} 
The injury probability chart shown in Fig. 1. represents the correlation of the AIS scale code with the HIC36 value as discovered by Alberto [13]

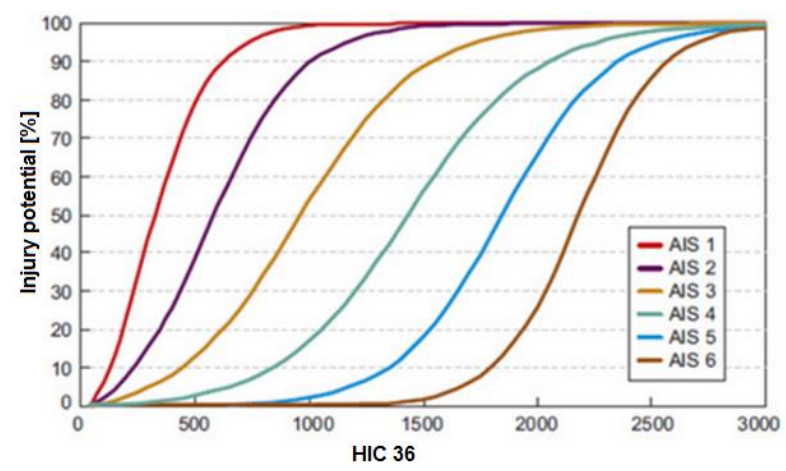

Fig. 1. Injury potential according to HIC 36 value in correlation with the AIS scale code.

The graph presents the evolution of the probability curves for AIS injury based on HIC36 value. Body tolerance according to the HIC criterion is 1000 and corresponds to a probability of $15-20 \%$ of the AIS- $4+$ injury. This increases to $60 \%$ for HIC $=1500$. The probability of $100 \%$ (death for the occupant) indicate an AIS-6 and occurs at HIC36 above 2500.

Sances researched the effects of airbag delay on the neck [14]. He observed that the peak tension force and extension moment in neck are well below the neck injury critical intercept values of $3200 \mathrm{~N}$ and extension moment of $60 \mathrm{Nm}$ proposed discovered by NHTSA. In contrast, in the case of late airbag deployment, the peak tension and extension moment are well above the neck injury tolerance. This suggests the high probability of serious neck injury with late deployment airbag.

An analysis by Frieder and Kumar using accident simulations with a virtual occupant model revealed that HIC36 values of the virtual dummy increased with the increase in airbag deployment delay. It was observed a percentage increase of the HIC 36 value by up to $600 \%$ in the event of an airbag deployment delay of $100 \mathrm{~ms}$. If the delay was $150 \mathrm{~ms}$, the gas force inside the airbag "throws" the occupant's head in the rear and it comes in contact with the head restraint causing injury by increased acceleration values of the head [15]. The study at hand follows up this analysis and test new variants including passenger injury risk a seatbelt pretensioning system.

\section{Occupant Model}

The occupant is represented by a multibody dummy, male 50th percent, MADYMO model integrated in PC Crash, used to simulate the kinematics of the occupant [16]. Dynamic simulation were conducted before in order to analyse the occupant behaviour using the LS-DYNA model [17]. By using mathematical models of the human body, the movement of the body elements can be imprinted extensively [18].

Using this model, airbag deployment and kinematics can be analysed for both the driver and the passenger along with the seatbelt pretension system. For the driver, the main characteristics of the airbag are presented in Fig. 2.

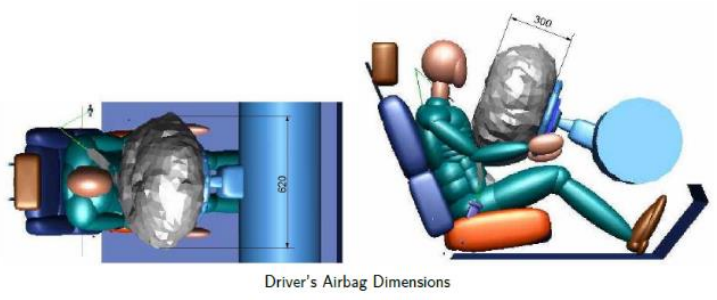

Fig. 2. Driver airbag technical specifications [16].

The inflation dimensions of the airbag are $300 \mathrm{~mm}$ in length and $620 \mathrm{~mm}$ in width. The total duration of inflation is $25 \mathrm{~ms}$, during this time, the massflow reaches $1.8 \mathrm{~kg} / \mathrm{s}$ in the first $10 \mathrm{~ms}$, then it drops to 0 in the next 40 $\mathrm{ms}$. The mass of the airbag expands from 0 to $30 \mathrm{~g}$ in 50 ms.

In Fig. 3, the technical specifications of the passenger airbag are presented in the similar way as the driver. It is to mention that on the passenger side, the airbag is much larger.

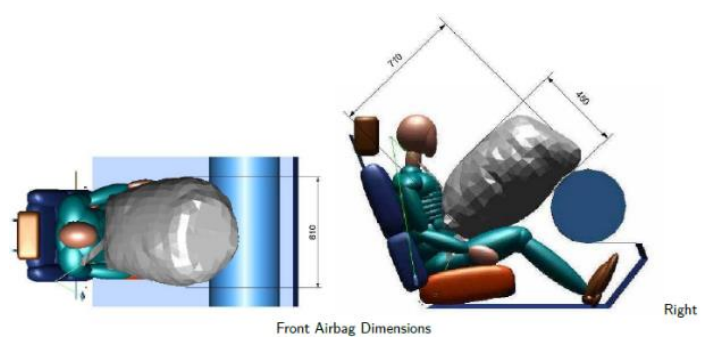

Fig. 3. Passenger airbag technical specifications [16].

The inflation dimensions of the passenger airbag are 450 $\mathrm{mm}$ in length, $610 \mathrm{~mm}$ in width and $710 \mathrm{~mm}$ in height. During inflation, the massflow goes from 0 to $3.3 \mathrm{~kg} / \mathrm{s}$ in the first $20 \mathrm{~ms}$, then it drops to almost 0 in the next $80 \mathrm{~ms}$. The mass of the airbag expands from 0 to $100 \mathrm{~g}$ in 100 $\mathrm{ms}$. It can be observed that the passenger airbag is 2 time larger that the driver side. The technical characteristics of the airbags are fixed and cannot be modified in the program, however, there are some key parameters that can be adjusted, such as the ignition time of the airbag and seatbelt pretention.

Using this screen, the ignition time could be set to a specific value, making this study possible. Also, the airbag and seatbelt could be either set as active, or one or both set as inactive. There are other settings can set be se such as the seatbelt configuration (only shoulder belt or lap belt) and if the current crash simulation is a side impact.

\section{Methods Used}

The method involves running simulations in PC-Crash using the MADYMO model where the ignition time of the airbag is modified in order to analyse the delay time and the occupant kinematics. Also, to validate the simulation, a frontal crash test will be conducted where the airbag and seatbelt are used. The crash test involves a stationary 
vehicle (VEH 1) where an occupant dummy is positioned, equipped with an accelerometer to measure the head acceleration and a striking vehicle (VEH 2) accelerated at $35 \mathrm{~km} / \mathrm{h}$.

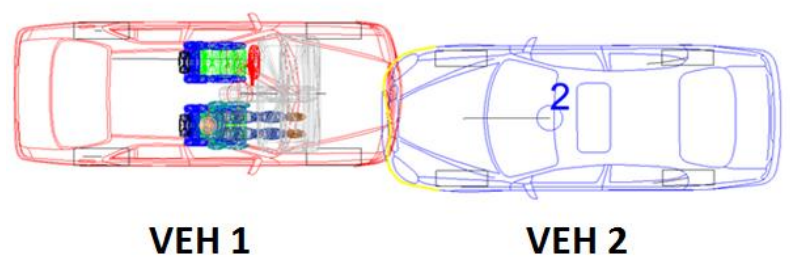

Fig. 4. Crash test configuration.

The crash test was filmed with a high speed camera in order to analyse the occupant kinematic. In Fig. 5. the kinematic analysis is presented. Also the comparison with the MADYMO simulation was done.

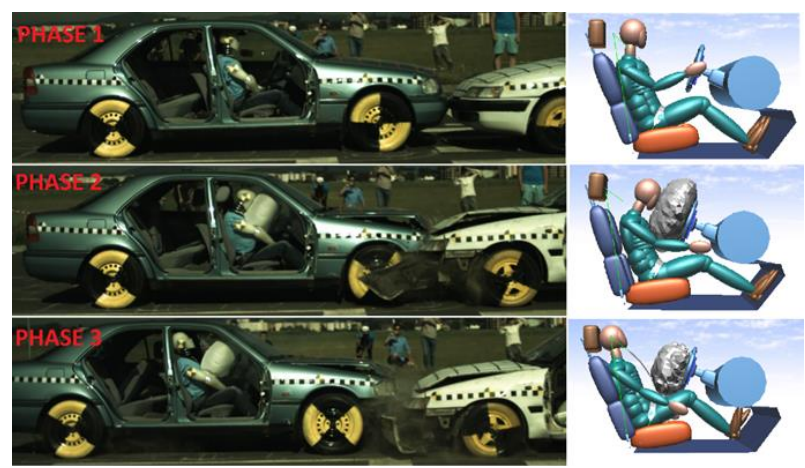

Fig. 5. Occupant kinematic comparison between the crash test and MADYMO model.

The crash was divided into 3 phases, the first phase consists the pre-impact phase when the vehicles make first contact. Phase 2 is the impact phase when the deformation of the vehicles take place, the energy is transferred and also the airbag and seatbelt pretention are deployed and limit the movement of the occupant. In phase 3, the vehicles detach and occupant's head rebound back and hits the headrest. It can be observed a good kinematic similarity between the crash test dummy and the MADYMO occupant.

\section{Results}

In Fig. 6. the vehicle velocities are presented during the collision. It can be seen that vehicle VEH 1 was standing still while VEH 2 was accelerated to the impact velocity of $34 \mathrm{~km} / \mathrm{h}$.

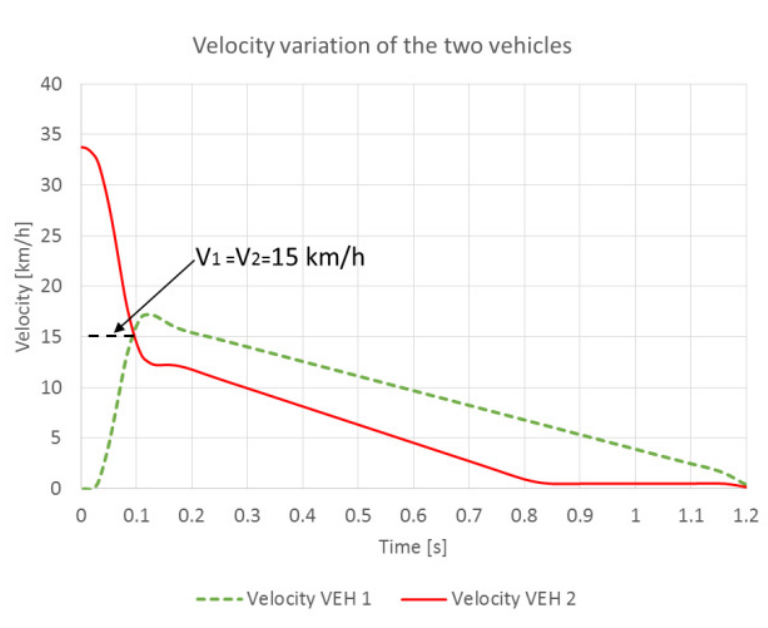

Fig. 6. Vehicles velocity variation during the collision.

The velocity variation shows that at $15 \mathrm{~km} / \mathrm{h}$, both vehicles had the same velocity, afterwards one vehicle slightly accelerates and the other tends to come to a stop. VEH 1 reached a velocity of about $17 \mathrm{~km} / \mathrm{h}$ during the first $100 \mathrm{~ms}$ of the impact then coming to a complete stop at the time of 1.2 seconds. VEH 2 registered a rapid decrease of velocity in the first $100 \mathrm{~ms}$ of impact from 34 to $13 \mathrm{~km} / \mathrm{h}$, afterward coming to a complete stop at 0.9 seconds. In Fig. 7., the head acceleration comparison of the occupants (test and simulation) is presented.

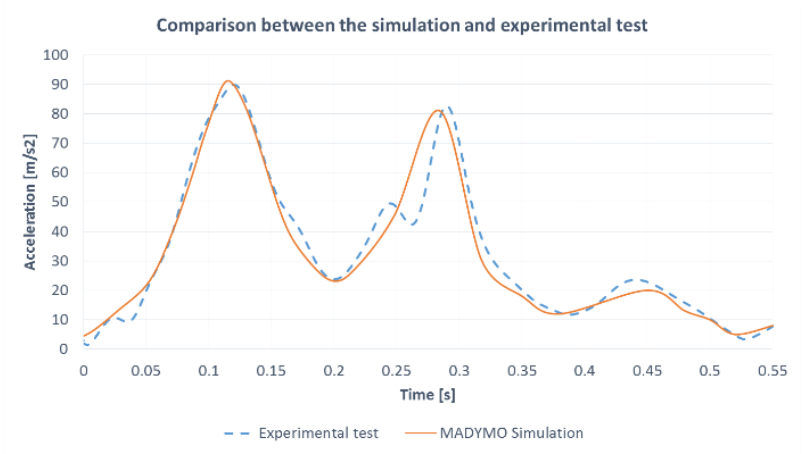

Fig. 7. Head acceleration comparison for the occupants.

The results of the simulation showed that the variation in the head acceleration resulted in two peaks, the first being the contact between the head and the airbag, and the second one between head and head restraint. The data obtained from the comparative analysis between the simulation and the experimental test indicated a high degree of similarity between them, with a $9 \%$ error.

Following the validation of the virtual occupant's behaviour with the actual collision test, the effects of the delayed airbags on the head were analysed. In order to assess the severity of injuries suffered by motor vehicle occupants due to delayed deployment of the airbag, it was necessary to carry out 7 simulations. In all these situations the occupant did not have the seat belt, but only the airbag. No passive safety system has been used in one of the simulations. In Fig. 8 the occupant movement is presented for the 7 times the airbag trigger time has varied at the time of $100 \mathrm{~ms}$ of the collision. The analysis was performed up to the $100 \mathrm{~ms}$ delay value. The acceleration reference value $(90 \mathrm{~m} / \mathrm{s} 2)$ corresponds to the $0 \mathrm{~ms}$ time. 


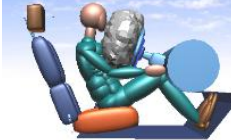

Delay $0 \mathrm{~ms}$

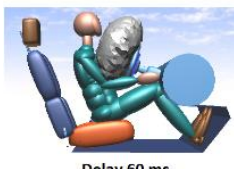

Delay $60 \mathrm{~ms}$

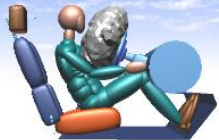

Delay $20 \mathrm{~ms}$

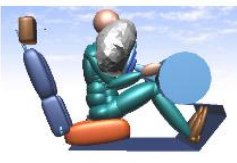

Delay $80 \mathrm{~ms}$

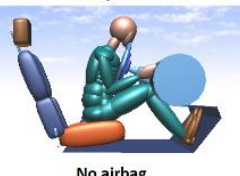

No airbas

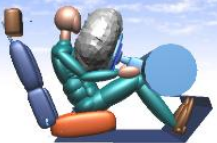

Delay $40 \mathrm{~ms}$

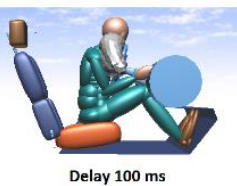

Delay $100 \mathrm{~ms}$
Fig. 8. Occupant kinematics at $100 \mathrm{~ms}$ of the collision when the airbag trigger time was modified.

It can be observed that the lack of passive safety systems results in collision of the occupant's torso with the steering wheel. The $0 \mathrm{~ms}$ delay is the ideal situation where the airbag is fully expanded at the moment of contact between the occupant and the airbag. Minor differences occur with delays of 20 and $40 \mathrm{~ms}$, but after $60 \mathrm{~ms}$, it can be seen that the position of the occupant approaches the situation where there are no passive safety systems. At $100 \mathrm{~ms}$ the occupant comes into contact with the steering wheel and the airbag deployment produces a head impact force. A further analysis of the occupant movement was done by observing the consequences at the time of 100 and $200 \mathrm{~ms}$ presented in Fig. 9.

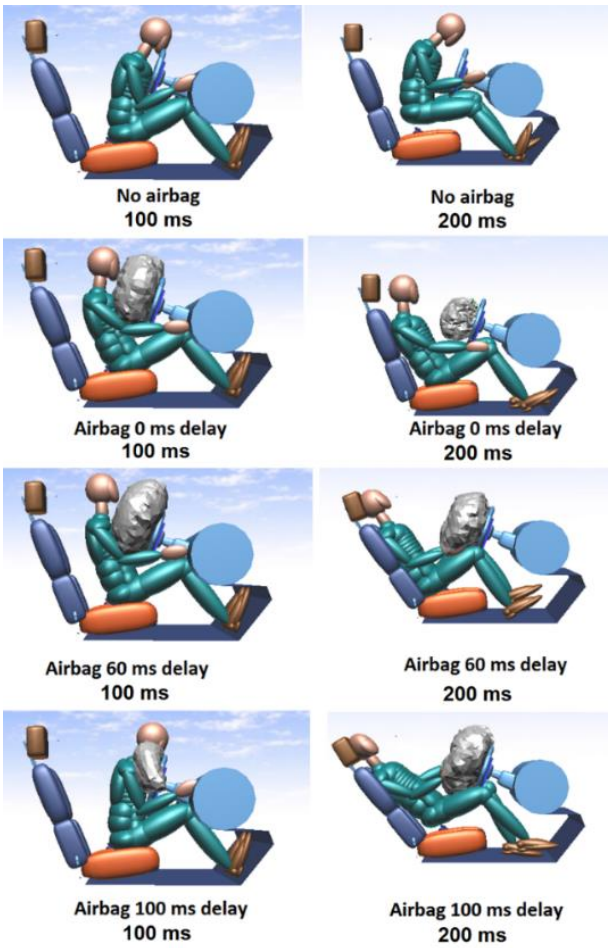

Fig. 9. Occupant kinematics at $100 \mathrm{~ms}$ and $200 \mathrm{~ms}$ of the collision when the airbag trigger time varied.

It can be seen that at $200 \mathrm{~ms}$, for the trigger times of 60 and $100 \mathrm{~ms}$, the force of the expanding airbag is so great, that it repels the occupant to the back of the seat generating and extra acceleration for the head. Following the simulations, a comparative analysis of the head acceleration was performed (Fig. 10).

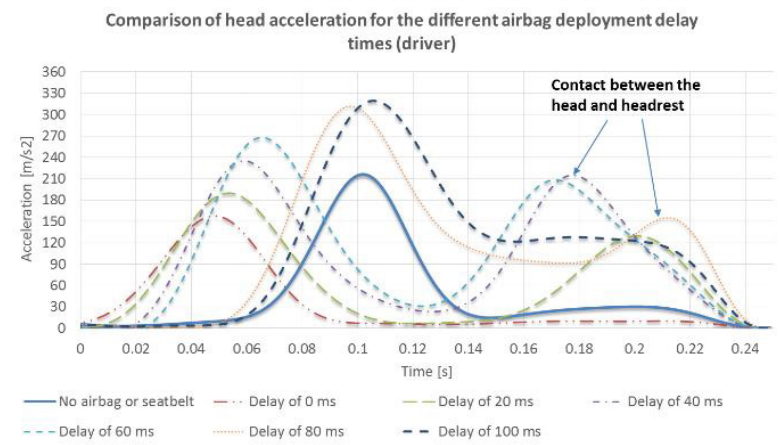

Fig. 10. Comparative head acceleration for the different airbag delay times.

From the diagram analysis, it was concluded that after the airbag trigger delay time of $80 \mathrm{~ms}$, the acceleration value at the head level doubles due to the expansion force of the airbag that is transmitted to the occupant's head. In the unfavourable situation where the belt and the airbag are missing, there was an increase in acceleration value of $38 \%$. To calculate the risk of injury of the occupant, the head injury criteria (HIC) was calculated.

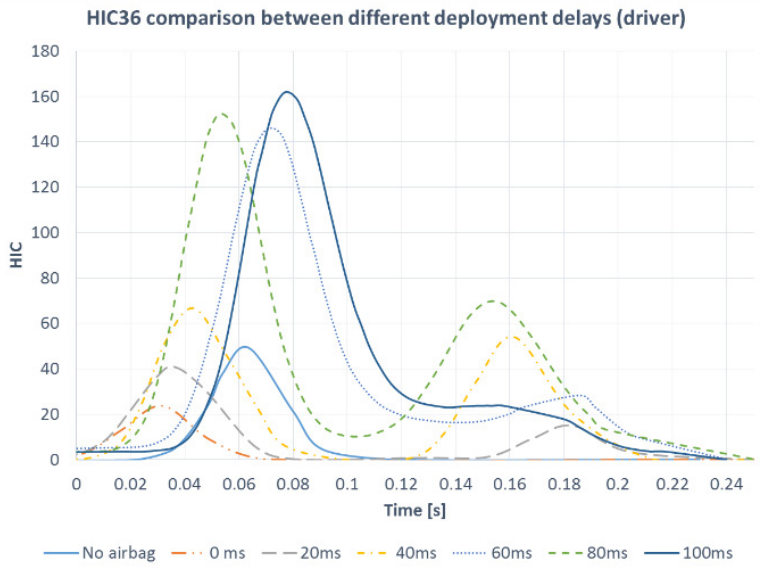

Fig. 11. HIC values for the different airbag delay times.

Head injury criteria (HIC) values have been used to express the occupant's injury potential by correlating them with the AIS severity scale. Since the maximum HIC values were below the threshold of 300 , the injury potential is considered to be low (AIS-1 - minor injuries). So Fig. 12 presents the likelihood of occurrence of lesions for the related study.

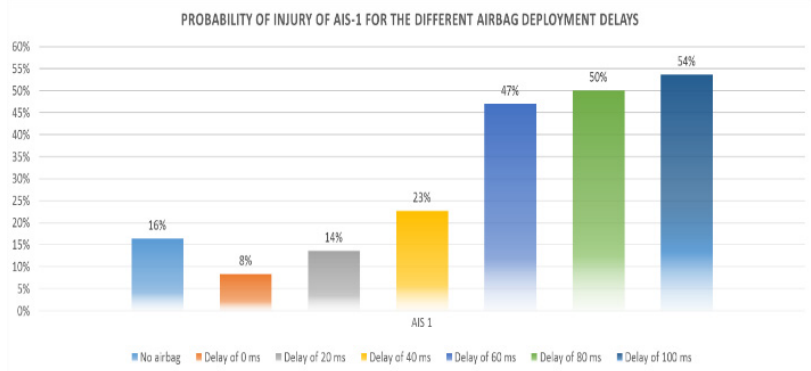


Fig. 12. The rate of occurrence of AIS-1 type lesions depending on the airbag deployment times.

The data revealed that the delay in triggering the airbag can induce the increase in head acceleration by $46 \%$, directly affecting the risk of injury. The explanation is due to the fact that the distance between the head and the steering wheel is reduced if the airbag is delayed by 80 $100 \mathrm{~ms}$, and at the moment of triggering, all the force generated by the expansion of the volume of gas inside the airbag is transmitted directly to the occupant's skull. The proper operation of the airbag ( $0 \mathrm{~ms}$ delay) requires that at the moment of contact between the head and the airbag, the airbag has reached the maximum expanded volume.

This study also contains analysis for the passenger airbag trigger delay. Using the same procedures as above, 3 simulations were performed (airbag and seatbelt with no delay, only the airbag with no delay and only the airbag with the delay of $40 \mathrm{~ms}$ ). In Fig. 13 the occupant kinematics are presented at the collisions time of 100 and $200 \mathrm{~ms}$ for the situations mentioned.

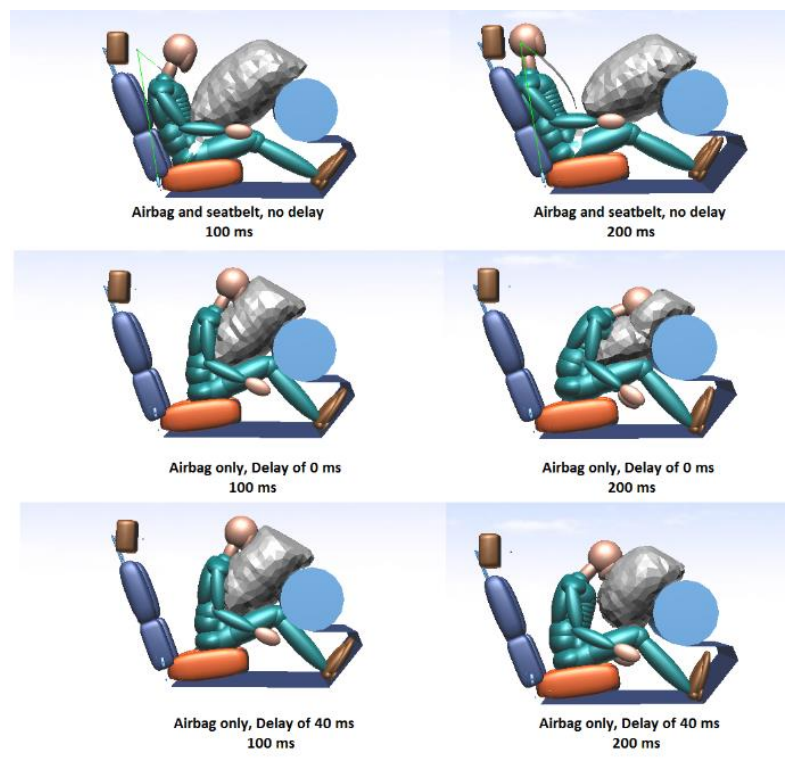

Fig. 13. Passenger occupant kinematics at $100 \mathrm{~ms}$ and $200 \mathrm{~ms}$ of the collision when the airbag trigger time varied.

It can be seen that when the airbag and seatbelt are used the occupant is well protected. When only the airbag is set with no delay, the occupant impact the airbag when it's completely inflated. With the delay of $40 \mathrm{~ms}$, at $200 \mathrm{~ms}$ time, the airbag force hits the occupant, but has lesser effect than the driver due to the fact that the distance between the head and the instrument panel is greater than in the case of the driver, the steering wheel is closer to the head. In Fig. 14 the head acceleration comparison is presented.

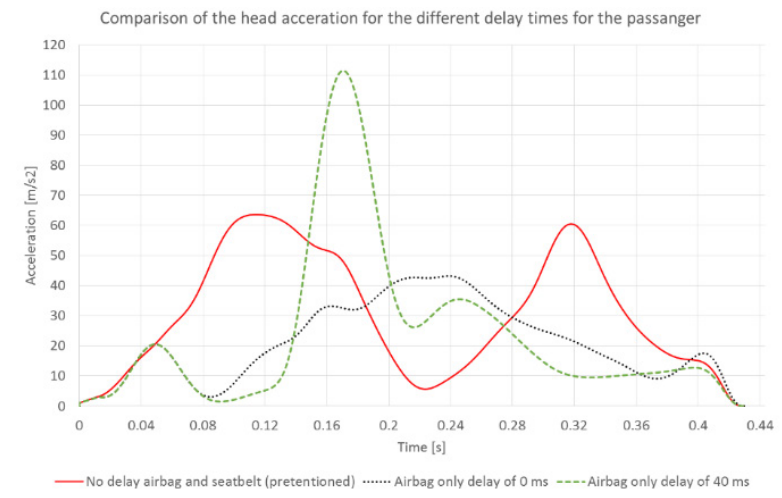

Fig. 14. Comparative head acceleration for the different airbag delay times (passenger).

With the seatbelt and airbag, the head acceleration is pretty low, with the value of $45 \mathrm{~m} / \mathrm{s} 2$. When only the airbag is present, with no delay, the acceleration increases by $44 \%$ and when the trigger time is delayed with $40 \mathrm{~ms}$, the acceleration increases even further by $144 \%$. To evaluate the injury potential in the similar way for the driver, HIC was calculated and presented in Fig. 15.

The HIC values are very low in this case, the maximum value being 11 when the airbag was delayed. In Fig. 19 the injury potential is presented in regards to the AIS scale.

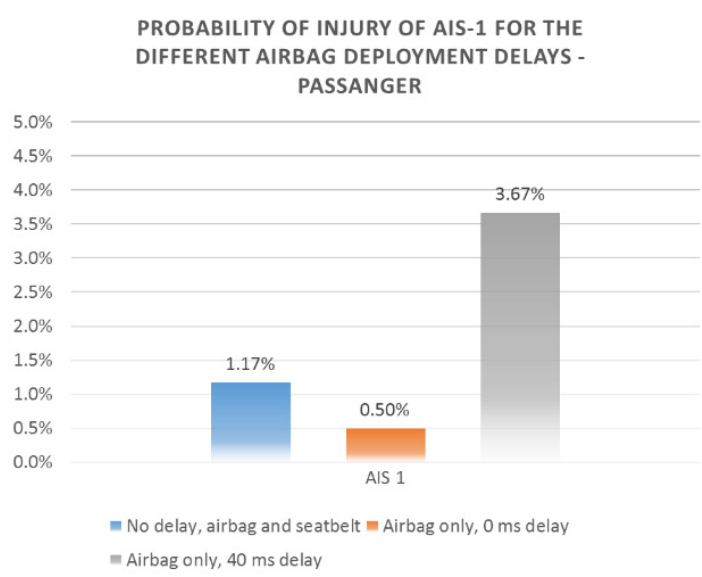

Fig. 15. The rate of occurrence of AIS-1 type lesions depending on the airbag deployment times (passenger).

Based on the AIS scale, the injury potential is very low (AIS-1) with the procent of $0.5 \%$ when the seatbelt and airbag are present and increases a bit, to $3.67 \%$ when the delay of the airbag was $40 \mathrm{~ms}$. These results show that airbag delay times does increase the injury potential for both the driver and passenger, but the passenger has a lesser chance of injury.

Further simulations were carried out to study the delay in triggering the seat belt pretensioner. Using the same impact configuration as in the previous analysis, it was intended to use only the seatbelt and varying the lag time when triggering it. The values for the delay times were: $0 \mathrm{~ms}, 10 \mathrm{~ms}, 20 \mathrm{~ms}$ and $30 \mathrm{~ms}$. In Fig. 16 the occupant's movement is presented for the related study. 


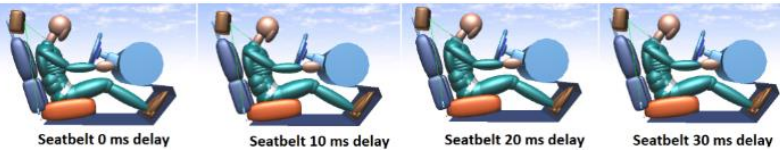

Fig. 16. The kinematics of the occupant according to the delay times when the pretensioner is triggered.

From the point of view of the occupant's behavior, small differences were found in all situations except for the 20 and $30 \mathrm{~ms}$ times where the movement was identical. The comparative analysis of head acceleration is shown in Fig. 17.

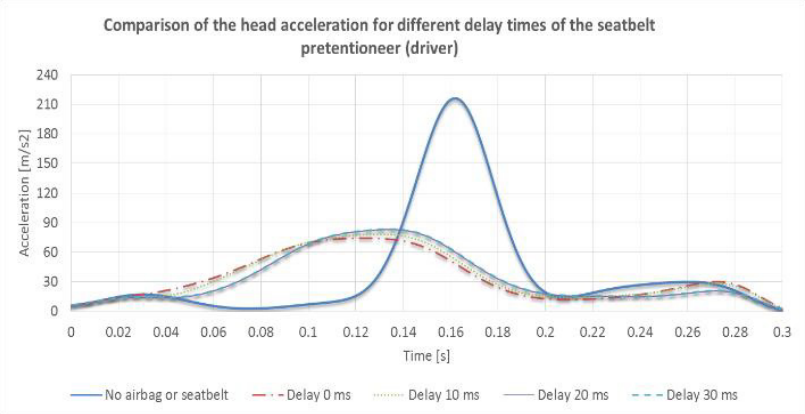

Fig. 17. Head acceleration comparison for different delay times of the seatbelt pretentioner.

From the analysis of the obtained data, it was noted the existence of small value differences for the 4 analysed situations, thus concluding that the delay of the pretensioning system does not have a massive impact on the degree of injury of the occupant.

\section{Conclusions}

Following the study regarding the influence of airbag deployment delay on the occupant injury potential, the following conclusions were drawn.

It has been found that by increasing the delay of the airbag deployment time in the event of a frontal impact, the probability of injury to the occupant's head increases by up to $46 \%$. Reducing the distance between the occupant's head and the dashboard / steering wheel when the airbag ignites would result in a force expansion of the gas that is transmitted to the occupant's head generating an extra acceleration and also throws back the occupant increasing the injury potential due to the impact between the head and headrest. Thus, an increase in injury probability of $8 \%$ was observed in the $0 \mathrm{~ms}$ delay of the airbag deployment, while a $100 \mathrm{~ms}$ delay resulted in a $54 \%$ increase in the head acceleration value. So the role of the airbag is reversed, it no longer has the role of cushioning the collision, but to generate injuries.

In the case of the passenger, similar results were obtained, although a lower overall injury risk was obtained. In this case, the increase of acceleration was of only $3.67 \%$ witch is considered negligible.

The results of the seatbelt pretensioning delay study showed that there were no major differences in head acceleration values due to the fact that the seat belt secures the occupant well in the seat regardless of the pretensioning system.

\section{References}

1. O. Oţăt, ACTA Univ. Cib. 1;67(1):115-20, (2015)

2. O. Oţăt, N. Dumitru, V. Oțăt, In AMM, 823, 187-192, (2016)

3. https://www.nhtsa.gov/equipment/airbags, (2017)

4. W.J. McFeely Jr, D.I. Bojrab, K.G. Davis and D.F. Hegyi, OHNS, 121(4): 367-73, (1999)

5. J.F. Huère, J.Y. Foret-Bruno and G. Faverjon, In Proceedings: International Technical Conference on the Enhanced Safety of Vehicles 2001, 6, (2001)

6. G.R Toganel, and A.O. Soica, In IOP Conference Series: Materials Science and Engineering, 252(1) 012020, (2017)

7. J. Kendall, IRSA, (2014)

8. http://www.lexomans.com/manguide-454.html, accessed, (2016)

9. B. McHenry, Head Injury Criterion and the ATB, (2004)

10. R. Eppinger, E. Sun, F. Bandak, M. Haffner, N. Khaewpong and M. Maltese, NHTSA, (1999)

11. B. Kang, S.W. Moon, J. Lim, B.H. Choi, In Proceedings of the Institution of Mechanical Engineers, Part D: Journal of Automobile Engineering. ; 229(7): 866-74, (2015)

12. M. Kramer, AUTOMOBILTECHN. Z ; 74(10), (1972)

13. http://www.biomeccanicaforense.com/criteri-divalutazione-del-trauma-cranico.html, (2017)

14. A. Sances, S. Kumaresan, W. Broadhead and K. Weiss, In Proceedings of the 2003 Summer Bioengineering Conference, 615-616 (2003)

15. R. Frieder, and S. Kumar, In ASME 2007 Summer Bioengineering Conference, 615-616, (2007)

16. S. Datentechnik., DSD, (2015)

17. O. Oţăt, S.C. Castravete and V. Oţăt, In Proceedings of the European Automotive Congress EAEC-ESFA 2015, 723-73, (2016)

18. D. Trusca, B. Benea, A. Soica and S. Tarulescu, In 2nd WSEAS Intrenational Conference on Multivariate Analysis and its Application in Science and Engineering MAASE09, (2009) 